\title{
Autoimmune Hepatitis is more severe in Asian Australians
}

\author{
Trinh $A^{1 *}$, Bohra $A^{1}$, Rogers $S^{1}$, Al-Ani $A^{2}$, Schneider $D^{2}$, Sood $S^{2}$ and Nicoll AJ ${ }^{1,2,3 *}$ \\ ${ }^{1}$ Department of Gastroenterology, Eastern Health, Melbourne, Australia \\ ${ }^{2}$ Department of Gastroenterology and Hepatology, The Royal Melbourne Hospital, Parkville, Australia \\ ${ }^{3}$ Eastern Health Clinical School, Monash University, Melbourne, Australia
}

\begin{abstract}
Increasingly there is more information in the literature on patients with Autoimmune Hepatitis (AIH) from Eastern countries, with evidence suggesting these patients present with a different clinical phenotype than patients from Western countries. A retrospective analysis of AIH patients at 2 Australian Health services with a mix of Asian and Caucasian patients, was performed. Data on 53 patients (11 Asian and 42 Caucasian) was assessed. Asian patients had a trend to higher AIH score at diagnosis (14.9 vs 13.4; $p=0.33$ ), and a higher percentage of Asian patients were cirrhotic at diagnosis (45\% vs $21 \%$; $p=0.22$ ). Only $36 \%$ of Asian patients had a complete response to standard therapy (normal ALT), compared to 57\% of Caucasian patients $(p=0.22)$. Relapse was more common in Asian patients (36\% vs $28 \%, p=0.62$ ). Asian Australian patients may have a more severe and more refractory clinical phenotype of AIH compared with Caucasian Australian patients.
\end{abstract}

\section{Introduction}

Autoimmune hepatitis (AIH) is a chronic progressive inflammatory liver disease that affects children and adults of all ethnicities and races. It has similarities with other autoimmune disorders with the pathogenesis hypothesised to involve a combination of environmental triggers, a loss of immunological self-tolerance and genetic predisposition. This induces a $\mathrm{T}$ cell-mediated immune attack upon liver antigens, leading to a progressive necro-inflammation of the liver $[1,2]$. AIH is considered relatively rare, with early prevalence studies from Europe showing 16 to 18 cases per 100,000 inhabitants [3-6]. However, further studies have shown that the prevalence and clinical expression seems to vary according to ethnicity [7]. Previous studies have suggested patients of Asian or other non-European background may have poorer outcomes [8-10]. The aim of this study was to compare the clinical phenotype and response to therapy of Caucasian and Asian Australian patients in a diverse, multicultural Australian city.

\section{Methods}

A retrospective analysis of liver databases was conducted of patients with known AIH from the last 10 years at two Australian tertiary Health services. The diagnosis of AIH was determined by the diagnostic criteria of definite or probable disease set by the International Autoimmune Hepatitis Group [11]. Phenotypic features including clinical features at presentation, response to standard therapy, and relapse rates were compared.

\section{Statistical analysis}

Differences in prevalence between ethnicities were compared by using the Student $t$ tests to compare continuous variables and chisquared test for categorical variables. A $p$ value of $<0.05$ was considered significant. Ethics was approved by the respective Human Research Ethics Committees at both health services.

\section{Results}

Between the two health services, 98 patients with AIH were identified. Twenty-eight patients were excluded because they were not
Caucasian or Asian. A further seventeen patients (all Caucasian) were excluded due to incomplete data on baseline characteristics, or response to treatment. Data was complete for 42 Caucasian and 11 Asian patients (four Chinese, four South East Asian and three South Asian). Baseline demographics are shown in table 1.

The majority of patients were female $(n=44,83 \%)$ with a higher female to male ratio in Asian compared to Caucasian patients (10:1 vs $17: 4 ; p=0.43)$. The median age at diagnosis was similar for the two groups; 53.6 years for Asians and 54.6 years for Caucasians $(p=$ 0.37). Caucasian patients demonstrated the typical bimodal age of presentation with $7 / 42(16.7 \%)$ patients presenting at age $<35$ years. In contrast, no Asian patients presented at age $<35$ years. Furthermore, Asian patients appeared to suffer less comorbid autoimmune disease compared with Caucasian patients $(36.4 \%$ vs $45.2 \%$; $p=0.60)$.

The AIH score at diagnosis was only marginally higher in the Asian patients (14.9 vs $13.4 ; p=0.33$ ), and a higher percentage of Asian patients were cirrhotic ( $45 \%$ vs $21 \% p=0.22$ ), but neither were statistically significant. At diagnosis, both the median ALT and the average total gamma globulin titres were higher in Asians compared to Caucasians $(349 \mathrm{IU} / \mathrm{L}$ vs $331 \mathrm{IU} / \mathrm{L} ; p=0.70$ and $20.9 \mathrm{~g} / \mathrm{L}$ vs $19.1 \mathrm{~g} / \mathrm{L} ; p=0.08$ respectively), however these differences did not reach statistical significance

Only $36 \%$ of Asians patients had a complete response to standard treatment (corticosteroids and azathioprine or 6-Mercaptopurine) with ALT returning to normal range, compared to $57 \%$ of Caucasian patients, $p=0.22$. Furthermore, a lower percentage of Asian patients had their total gamma globulins returned to normal with treatment compared to Caucasian patients $(57.1 \%$ vs $63.6 \%$; $p=0.08)$.

Biochemical relapse was more common in Asian patients (36\% vs $28 \% ; p=0.62)$. Second and third line therapies such as mycophenolate,

${ }^{\star}$ Correspondence to: Trinh Andrew, Department of Gastroenterology, Eastern Health, Melbourne, Victoria, Australia, E-mail: Andrew.Trinh@mh.org.au

Received: June 11, 2018; Accepted: June 25, 2018; Published: June 29, 2018 
Table 1. Baseline characteristics

\begin{tabular}{|l|l|l|l|}
\hline & $\begin{array}{l}\text { Caucasians } \\
\text { n (\%) }\end{array}$ & $\begin{array}{l}\text { Asians } \\
\text { n (\%) }\end{array}$ & \\
\hline Number (\% of total) & $42(79.2 \%)$ & $11(20.8 \%)$ & \\
\hline Nationality & & 4 & \\
\hline Chinese & 4 & \\
\hline SE Asian & $34: 8$ & $10: 1$ & $p=0.43$ \\
\hline South Asian & $54.6 \pm 18.8$ & $53.6 \pm 12.2$ & $p=0.37$ \\
\hline Female: Male & $7(16.7 \%)$ & $0(0 \%)$ & \\
\hline Median Age (years) \pm IQR & $35(83.3 \%)$ & $11(100 \%)$ & $p=0.60$ \\
\hline Age $<35$ years & $19(45.2 \%)$ & $4(36.4 \%)$ & $p=0.33$ \\
\hline Age $>35$ years & 13.4 & 14.9 & $p=0.22$ \\
\hline $\begin{array}{l}\text { Comorbid Autoimmune } \\
\text { Disease }\end{array}$ & $9(21.4 \%)$ & $5(45.5 \%)$ & $p=0.70$ \\
\hline $\begin{array}{l}\text { Mean AIH score (at } \\
\text { diagnosis) }\end{array}$ & $331 \pm 1032$ & $349 \pm 538$ & $p=0.08$ \\
\hline Cirrhosis at diagnosis & $19.1 \pm 12.5$ & $20.9 \pm 19.1$ & \\
\hline $\begin{array}{l}\text { ALT at diagnosis (IU/L) } \\
\text { Median } \pm \text { IQR }\end{array}$ & $\begin{array}{l}\text { Mean Total Gamma Globulin } \\
\text { (g/L) } \\
\text { Median } \pm \text { IQR }\end{array}$ & & \\
\hline
\end{tabular}

budesonide, methotrexate and cyclosporine were used similarly in Asian patients and Caucasian patients (54.5\% compared to $52.4 \%$, $p=0.90)$.

\section{Discussion}

This study adds to the current literature that Asian patients with AIH often have a different clinical phenotype to Caucasians, and this should be taken into consideration when planning management. With a multicultural population that includes large numbers of both Asian and Caucasian individuals, the city of Melbourne provides an opportune cohort to investigate these differences in greater detail. Our pilot data suggests Asian patients appear to have a different clinical phenotype for autoimmune hepatitis compared with Caucasian patients in our cohort, with a possible trend towards more severe and treatment refractory disease. This is the first Australian study to describe and characterize the differences between these two groups. Although there were no significant results, our study provides interesting preliminary results which we hope to expand to other Australian health services given Australia's multicultural population.

Ethnic differences in AIH have previously been considered. A study from King's College Hospital in the United Kingdom compared their 12 non-European AIH patients with 180 European AIH patients [8]. However, the non-European cohort included only 5 Asian patients and were significantly younger compared to the Europeans. They found no significant differences between the two groups in the proportions presenting acutely or with cirrhosis, and similar to our study, a significantly lower proportion of non-European patients showed a complete initial response to standard therapy. A study from the United
States comparing Caucasians, Asians and Hispanics demonstrated similar findings [9]. In their cohort, Asians had a higher AIH score at diagnosis compared to Caucasians, and Asians were more likely to be cirrhotic. The Kaplan-Meier survival analysis showed a trend toward poorer outcomes among Asians.

Our study was limited by factors typical of retrospective research, including lack of complete data for all patients, especially detailed information pertaining to the severity of illness, HLA status and details of immunosuppressive therapies. Furthermore, the sample size of our cohort was small, in particular our small number of Asian patients, hence there was insufficient power to demonstrate a statistical significant difference between our two cohorts.

In summary, our study presents a comparison between the clinical phenotypes of Caucasian and Asian Australian patients with AIH. It demonstrates that Asian patients may potentially have a different clinical phenotype compared to Caucasian patients, with a possible trend towards more severe and more treatment refractory disease further highlighting the race/ethnicity-specific variations in the clinical features of autoimmune hepatitis.

\section{References}

1. Liberal R, Longhi MS, Mieli-Vergani G, Vergani D (2011) Pathogenesis of autoimmune hepatitis. Best practice \& research Clinical gastroenterology 25: 653-664. [Crossref]

2. Vergani D, Mieli-Vergani G (2008) Aetiopathogenesis of autoimmune hepatitis. World $J$ Gastroenterol 14: 3306-3312. [Crossref]

3. van Gerven NM, Verwer BJ, Witte BI, van Erpecum KJ, van Buuren HR, et al. (2014) Epidemiology and clinical characteristics of autoimmune hepatitis in the Netherlands. Scand J Gastroenterol 49: 1245-1254. [Crossref]

4. Boberg KM, Aadland E, Jahnsen J, Raknerud N, Stiris M, et al. (1998) Incidence and prevalence of primary biliary cirrhosis, primary sclerosing cholangitis, and autoimmune hepatitis in a Norwegian population. Scand J Gastroenterol 33: 99-103. [Crossref]

5. Feld JJ, Heathcote EJ (2003) Epidemiology of autoimmune liver disease. $J$ Gastroenterol Hepatol 18: 1118-1128. [Crossref]

6. Werner M, Prytz H, Ohlsson B, Almer S, Bjornsson E, et al. (2008) Epidemiology and the initial presentation of autoimmune hepatitis in Sweden: a nationwide study. Scand J Gastroenterol 43: 1232-1240. [Crossref]

7. Czaja AJ (2013) Autoimmune hepatitis in diverse ethnic populations and geographical regions. Expert Rev Gastroenterol Hepatol 7: 365-385. [Crossref]

8. Zolfino T, Heneghan MA, Norris S, Harrison PM, Portmann BC, et al. (2002) Characteristics of autoimmune hepatitis in patients who are not of European Caucasoid ethnic origin. Gut 50: 713-717. [Crossref]

9. Wong RJ, Gish R, Frederick T, Bzowej N, Frenette C (2012) The impact of race ethnicity on the clinical epidemiology of autoimmune hepatitis. J Clin Gastroenterol 46: 155-161. [Crossref]

10. Levy C, Naik J, Giordano C, Mandalia A, O'Brien C, et al. (2014) Hispanics with primary biliary cirrhosis are more likely to have features of autoimmune hepatitis and reduced response to ursodeoxycholic acid than non-Hispanics. Clin Gastroenterol Hepatol 12:1398-1405. [Crossref]

11. Johnson PJ, McFarlane IG (1993) Meeting report: International Autoimmune Hepatitis Group. Hepatology 18: 998-1005. [Crossref]

Copyright: (C2018 Trinh A. This is an open-access article distributed under the terms of the Creative Commons Attribution License, which permits unrestricted use, distribution, and reproduction in any medium, provided the original author and source are credited. 